\title{
Efficacy of Natural Deep Eutectic Solvents for Extraction of Hydrophilic and Lipophilic Compounds from Fucus vesiculosus
}

\author{
Ekaterina D. Obluchinskaya ${ }^{1}$ (), Olga N. Pozharitskaya ${ }^{1}$, Lyubov V. Zakharova ${ }^{1}$, Anna V. Daurtseva ${ }^{1}$, \\ Elena V. Flisyuk ${ }^{2}$ and Alexander N. Shikov ${ }^{1,2, *(\mathbb{D})}$ \\ 1 Murmansk Marine Biological Institute of the Russian Academy of Sciences (MMBI RAS), Vladimirskaya, 17, \\ 183010 Murmansk, Russia; obluchinskaya@mmbi.info (E.D.O.); olgapozhar@mail.ru or \\ pozharitskaya@mmbi.info (O.N.P.); zakharova@mmbi.info (L.V.Z.); tkach@mmbi.info (A.V.D.) \\ 2 Department of Technology of Pharmaceutical Formulations, St. Petersburg State Chemical Pharmaceutical \\ University, Prof. Popov, 14, 197376 Saint-Petersburg, Russia; elena.flisyuk@pharminnotech.com \\ * Correspondence: alexs79@mail.ru
}

check for updates

Citation: Obluchinskaya, E.D.; Pozharitskaya, O.N.; Zakharova, L.V.; Daurtseva, A.V.; Flisyuk, E.V.;

Shikov, A.N. Efficacy of Natural Deep Eutectic Solvents for Extraction of Hydrophilic and Lipophilic Compounds from Fucus vesiculosus. Molecules 2021, 26, 4198. https:// doi.org/10.3390/molecules26144198

Academic Editor: Jeongmi Lee

Received: 8 June 2021

Accepted: 7 July 2021

Published: 10 July 2021

Publisher's Note: MDPI stays neutral with regard to jurisdictional claims in published maps and institutional affiliations.

Copyright: (c) 2021 by the authors. Licensee MDPI, Basel, Switzerland. This article is an open access article distributed under the terms and conditions of the Creative Commons Attribution (CC BY) license (https:/ / creativecommons.org/licenses/by/ $4.0 /)$.

\begin{abstract}
The impact of the composition of natural deep eutectic solvents (NADES) and extraction conditions on the simultaneous extraction of hydrophilic ascorbic acid (AA), phlorotannins (TPhC), and lipophilic fucoxanthin (FX) from Fucus vesiculosus was investigated for the first time. In biological tests, the NADES extracts showed the promising ability to scavenge DPPH radicals. A positive correlation was observed between DPPH scavenging activity and AA, TPhC, and FX contents. We calculate the synergistic effect of antioxidants extracted by NADES from F. vesiculosus based on the mixture effect (ME). The addition of $30 \%$ water to the NADES and the prolongation of sonication time from $20 \mathrm{~min}$ up to $60 \mathrm{~min}$ were favorable for the ME. The ME for extracts with the NADES was increased by two folds (ME > 2). In contrast, conventional extraction by maceration with steering at $60{ }^{\circ} \mathrm{C}$ does not lead to the synergistic effect $(\mathrm{ME}=1)$. It is notable that the NADES provides high stability and preserves the antioxidant activity of the extracts from F. vesiculosus during storage.
\end{abstract}

Keywords: ascorbic acid; fucoxanthin; phlorotannins; antioxidant; brown seaweeds; synergy; storage stability

\section{Introduction}

The development of the environmentally friendly and efficient extraction of biologically active compounds from phytobiomass is a modern trend in the pharmaceutical, cosmetical, and food industries. The natural deep eutectic solvents (NADES) are a promising alternative to conventional organic solvents and gained popularity because they are green, non-toxic, biodegradable, and recyclable [1,2]. The NADES were proposed by a group of scientists who discovered a third liquid phase in plants, which has a phenomenal dissolving power for small molecules and biopolymers with low or non-water solubility [3]. Such solvents consist of the metabolites of living cells: sugars, organic acids, ammonium, and phosphonium salts, etc. The solubility of the target compounds in the NADES significantly increases due to the formation of hydrogen bonds with solutes $[4,5]$.

To be predominantly polar liquids, NADES have been used for the extraction of alkaloids [6], anthocyanins [7-9], glycosides of phenyletanes and phenylpropanoids [10], and polysaccharides [11]. NADES could be customized for the extraction of less polar aglycones of flavonoids [12], anthraquinones [13], astaxanthin [14], curcumin [15], glycyrrhizic acid [16], iridoids [17], and steroidal saponins [18]. Hydrophobic terpenes and fatty acid-based NADES allowed for the isolation of carotenoids, free fatty acids, and pheophytin [19]. Recently, a biphasic system based on deep eutectic solvents was proposed for the simultaneous extraction of high polarity chlorogenic acid, quercetin, anthocyanidins, and a low polarity compound artemisinin from Artemisia [20]. Several papers report the application of NADES for the recovery of bioactive compounds from seaweeds [19,21-24]. 
Brown seaweeds, particularly, Fucus vesiculosus, are rich sources of biologically active metabolites: amino acids [25], fucoxanthin and other carotenoids [26], chlorophylls [27], fucoidan [28-30], polyunsaturated fatty acids [31,32], and polyphenols [33,34], etc.

Brown seaweeds, compared with other seaweeds, contain higher levels of polyphenols, which shows potent antioxidant activity. F. vesiculosus polyphenols are represented mainly by very hydrophilic phlorotannins-polymerized phloroglucinol (1,3,5-trihydroxybenzene) units $[25,35,36]$. Another hydrophilic compound of interest in brown seaweeds is ascorbic acid. It was estimated that the daily consumption of $100 \mathrm{~g}$ of seaweed covers $2 / 3$ of the recommended doses of ascorbic acid for humans [37]. One of the main lipophilic compounds produced by brown seaweeds is carotenoid fucoxanthin, which is responsible for algae color [38]. Fucoxanthin is a well-established antioxidant according to in vitro and in vivo investigations $[39,40]$.

The antioxidant effects of seaweed extracts have been confirmed both in vitro and in vivo [36,41-43]. Epidemiological observations provide evidence that dietary supplementation with seaweeds reduces the risk of numerous diseases associated with oxidative stress [44-46]. Therefore, we consider using the antioxidant test as an indicator for the biological activity of novel extracts from F. vesiculosus obtained by the application of NADES. Due to peculiar characteristics, including chemical complexity, susceptibility to oxidation, and specific polarity, the simultaneous extraction of hydrophilic and lipophilic compounds is a challenging process.

In this study, NADES were tuned to simultaneously extract hydrophilic and lipophilic bioactive compounds from $F$. vesiculosus. The efficacy of extraction was evaluated by the analysis of the content of ascorbic acid, fucoxanthin, and phlorotannins. The biological activity of the extracts was monitored using an antioxidant activity test. Additionally, the impact of some compounds on antioxidant activity and the ability of NADES for the stabilization of extracts was studied.

\section{Results and Discussion}

\subsection{NADES Tuning}

The widespread use of toxic solvents in chemical, pharmaceutical, and other industries places a heavy burden on the environment. The green extraction of biologically active compounds from phytobiomass with NADES is essential for rational environmental management $[47,48]$. NADES, mainly synthesized from polar components, are well studied for the recovery of hydrophilic compounds. In this study, we aimed to extract both hydrophilic and lipophilic compounds from F. vesiculosus. Based on literature data and the results of our preliminary experiments we have prepared the two most promising NADES (Table 1).

Table 1. Natural deep eutectic solvents (NADES) used for extraction.

\begin{tabular}{cccc}
\hline NADES Code & Components & Molar Rate & Appearance \\
\hline NADES1 & Lactic acid:Choline & $3: 1$ & $\begin{array}{c}\text { Viscous transparent } \\
\text { chloride }\end{array}$ \\
NADES2 & Lactic acid:Glucose: $\mathrm{H}_{2} \mathrm{O}$ & $5: 1: 3$ & Transparent liquid \\
\hline
\end{tabular}

Although advanced extraction techniques, such as pressurized liquid extraction [49], supercritical fluid extraction [50], and microwave-assisted extraction [51] have been implemented, ultrasound-assisted extraction (UAE) is the most commonly employed method for the recovery of biologically active compounds from brown seaweeds [23,43]. Whereas percolation (PE) is recognized as an exhaustive extraction method [52]. Ethanol has been recommended as a suitable solvent for extraction of ascorbic acid [53], phlorotannins [42,51], and fucoxanthin $[54,55]$. The structures of the analyzed compounds and components of NADES are presented in Figure 1. Typical chromatograms of reference compounds and NADES extracts are available in Supplementary materials (Figures S1-S7). 
<smiles>O=C1OC(C(O)CO)C(O)=C1O</smiles><smiles>Oc1cc(O)cc(O)c1</smiles>

Ascorbic acid<smiles>C[N+](C)(C)C=CCO</smiles>

Choline chloride<smiles>CC(=O)OC1CC(C)(C)C(=C=CC(C)=CC=CC(C)=CC=CC=C(C)C=CC=C(C)C(=O)CC23[C@@H](O)CC2(C)C[C@H](O)CC3(C)C)C(C)(C)C1</smiles>

Fucoxanthin<smiles>CC(O)C(=O)O</smiles>

Lactic acid

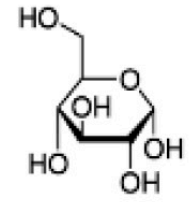

Glucose

Figure 1. The structures of ascorbic acid, phloroglucinol, fucoxanthin, choline chloride, lactic acid, and glucose.

The efficacy of the extraction of hydrophilic and lipophilic compounds from F. vesiculosus with NADES using UAE was compared with that of ethanol using PE (Table 2).

Table 2. The content of hydrophilic-ascorbic acid (AA), total phlorotannins (TPhC), and lipophilicfucoxanthin (FX) compounds from Fucus vesiculosus after UAE and PE (mean \pm standard deviation).

\begin{tabular}{cccc}
\hline Solvent & $\begin{array}{c}\text { AA, } \\
\text { mg/g DW Seaweed }\end{array}$ & $\begin{array}{c}\text { TPhC, } \\
\text { mg/g DW Seaweed }\end{array}$ & $\begin{array}{c}\text { FX, } \\
\text { mg/g DW Seaweed }\end{array}$ \\
\hline UAE, NADES1 & $0.058 \pm 0.010$ & $17.2 \pm 3.7$ & $0.24 \pm 0.03$ \\
UAE, NADES2 & $0.093 \pm 0.010$ & $9.3 \pm 0.9$ & $0.17 \pm 0.02$ \\
PE, EtOH & $0.80 \pm 0.01$ & $71.7 \pm 0.4$ & $1.10 \pm 0.02$ \\
\hline
\end{tabular}

$\mathrm{UAE}$ (ultrasound-assisted extraction) at a $1: 10(\mathrm{w} / \mathrm{v})$ seaweed to solvent ratio, $25^{\circ} \mathrm{C}, 20 \mathrm{~min}$; $\mathrm{PE}-$ maceration with $\mathrm{EtOH}$ for $24 \mathrm{~h}$, and percolation at a 1:10 $(w / v)$ seaweed to solvent ratio, $25^{\circ} \mathrm{C}$.

PE provided the maximal recovery of all hydrophilic and lipophilic compounds from seaweeds (Table 1). NADES1 has more potential for recovery of TPhC and FX when compared with NADES2. While NADES2 was more suitable for the extraction of AA (Table 2). The addition of water to NADES led to a decrease in the viscosity and in the surface tension of the solvents, which had a positive impact on the mass transfer from the seaweed cells into the extract [4]. The water $(10-40 \%, w / w)$ was added to both NADES to facilitate the efficacy of extraction (Figure 2).

The extraction yields of the hydrophilic ascorbic acid and phlorotannins significantly raised as the water content in the NADES increased. The compounds rich in hydroxyl groups like AA and TPhC are good hydrogen donors and preferably form bonds with hydrogen bond acceptors like choline chloride [23,56]. Although recently, AA has been introduced for the preparation of NADES [56,57], to the best of our knowledge, we report the extraction of ascorbic acid from seaweeds with NADES for the first time. Carotenoid FX is practically insoluble in water. Thus, the addition of water to both NADES does not have a statistically significant effect on the recovery of FX (Figure 2). Organic toxic solvents are commonly used for FX extraction from seaweeds [58]. Recently, Roy et al. (2021) reported on the extraction of another carotenoid astaxanthin from a marine species with NADES [59]. We have not found information about the recovery of FX by NADES in the available literature. This is the first time NADES are suggested for the extraction of fucoxanthin from F. vesiculosus. 


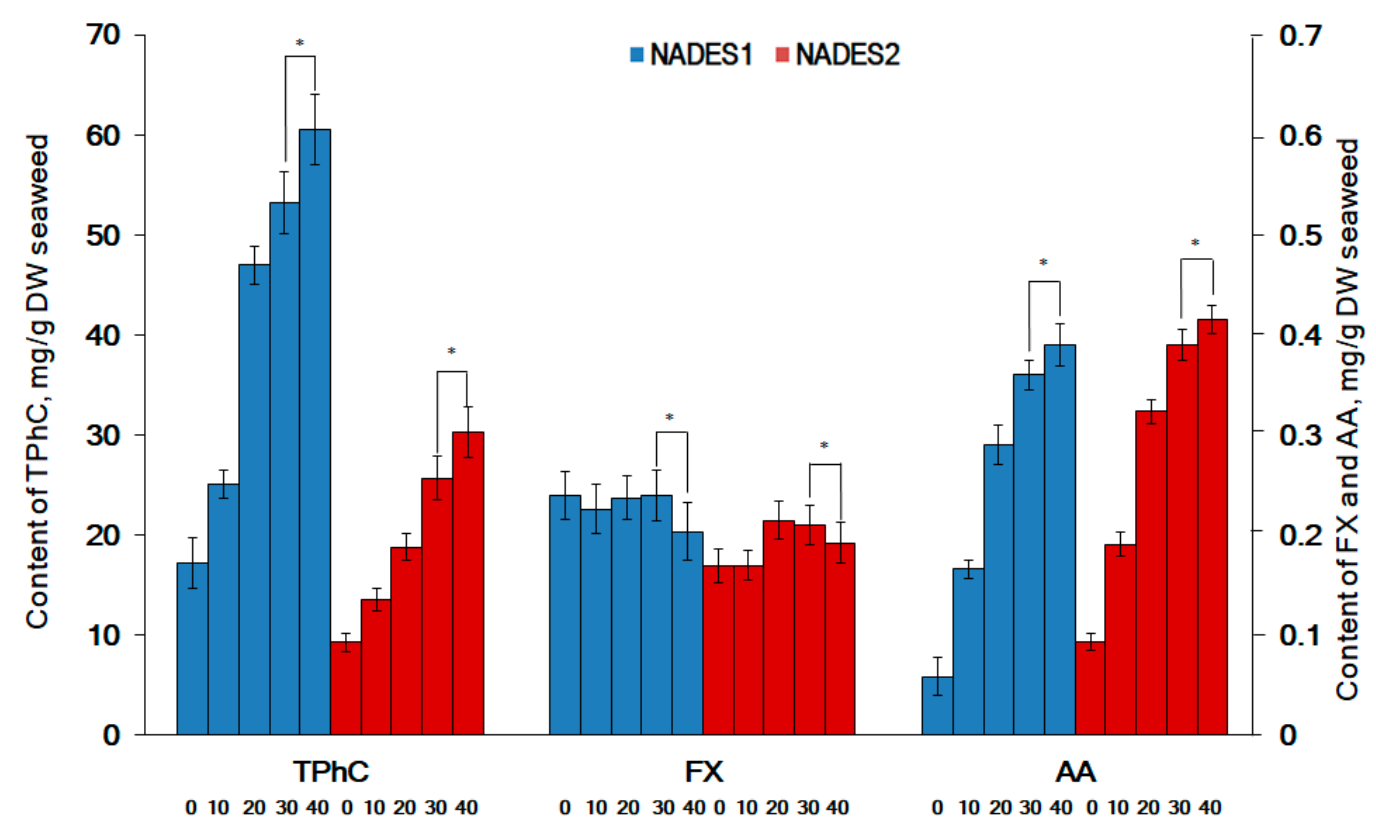

Water content in NADES, \%

Figure 2. The effect of water content in NADES on the extraction efficacy of total phlorotannins (TPhC), fucoxanthin (FX), and ascorbic acid (AA) from F. vesiculosus. All experiments were performed using UAE at a 1:10 $(w / v)$ seaweed to solvent ratio at $25{ }^{\circ} \mathrm{C}$ for $20 \mathrm{~min}$. Water content $0,10,20,30$, and $40 \%(v / v)$. ${ }^{*}$ The difference is not statistically significant, $p>0.05$.

The addition of water to both NADES, up to $30 \%$, significantly improved the extraction yield of hydrophilic compounds. While an increase of water up to $40 \%$ had not resulted in a statistically significant increase of extracted compounds (Figure 2). This is in line with other authors who recommend a maximum limit of 30\% of water in NADES [60-62]. Therefore, for subsequent experiments, we consider the addition of $30 \%$ water to both NADES.

\subsection{Extraction Conditions Tuning}

The duration of the extraction significantly affects the performance and selectivity of the recovery of active principles from seaweeds $[62,63]$. We observed that the extension of the extraction time leads to an increase in the yield of tested compounds (Figure 2). The most promising increase was observed for FX (up to 89.5-91.3\%, when compared to extraction by PE) (Table 1). This is consistent with the literature data that indicates a positive effect of the extraction time on the yield of FX from seaweeds [54,55]. Notably, $\mathrm{TPhC}$ values after 60 min sonication with both NADES (Figure 2) were equal to the efficacy of PE (Table 1). This could be explained by the more complete interaction of NADES via numerous hydrogen bonds with the hydroxyl groups of phlorotannins. This promotes better solubilization of phlorotannins after prolonged sonication [64]. Additionally, polyphenols interact with NADES to form polymers over the longer extraction period [65].

Prolonged sonication for $60 \mathrm{~min}$ resulted in an increase of AA extraction by 55\%, compared with 20 min sonication in the case of NADES1. The sonication for 60 min was not favorable for AA extraction by NADES2 (Figure 3). Ultrasonic waves generate intensive cavitation in the extraction medium, resulting in the formation and explosion of cavitation bubbles [66]. These generate mechanical shear forces which destroyed the seaweed cell, thereby facilitating the release of active compounds into the solvent phase. Furthermore, acoustic streaming causes the mixing effect, which enhances the contact between solvents and active compounds and increases extraction performance [67]. Otherwise, the intensive mixing and formation of bubbles resulted in saturation of the extraction media with air. It was shown that the air's oxygen heavily induced the degradation of AA in juices after $60 \mathrm{~min}$ of stirring at $25^{\circ} \mathrm{C}$ [68]. All wave phenomena during UAE were attenuated in viscous media. Due to the higher water content, NADES2 has less viscosity when compared 
to NADES1. The lower AA content in NADES2 could be associated with its degradation during the $60 \mathrm{~min}$ of sonication in our experiment.

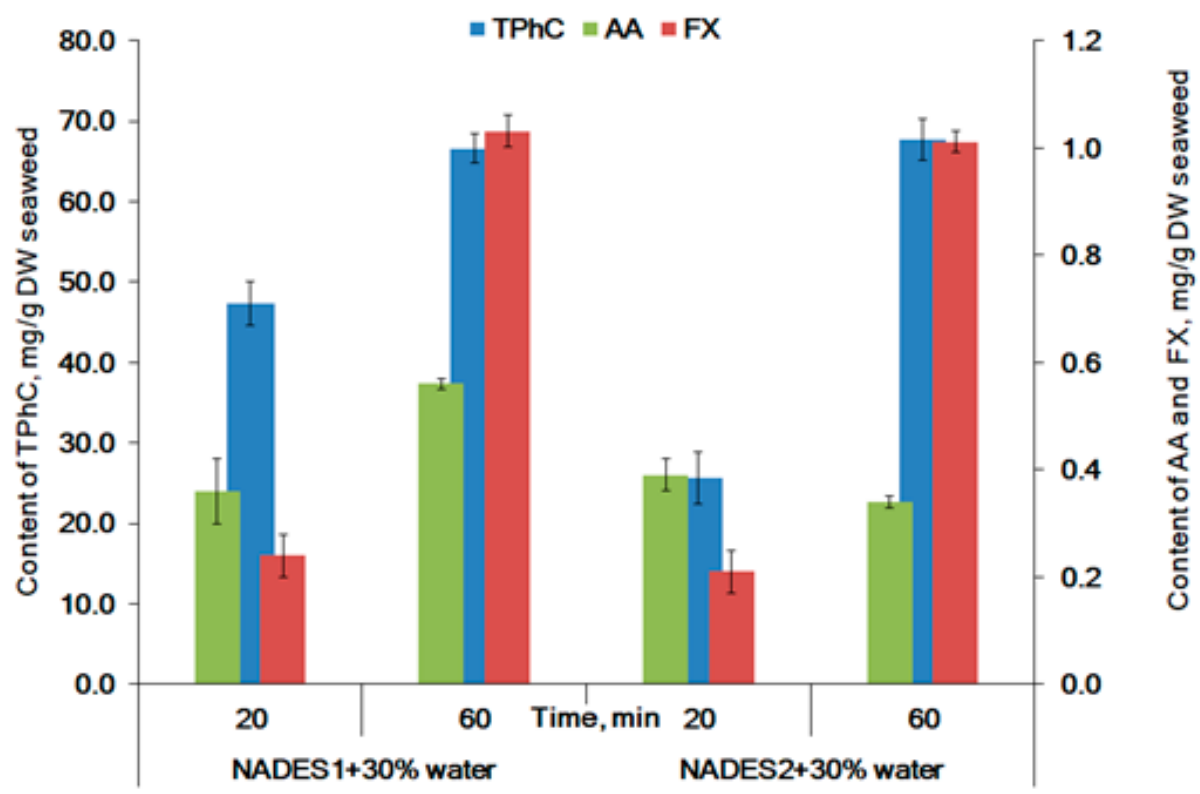

Figure 3. The effect of extraction time on the recovery of ascorbic acid (AA), total phlorotannins $(\mathrm{TPhC})$, and fucoxanthin (FX) from F. vesiculosus by UAE at a 1:10 $(w / v)$ seaweed to solvent ratio at $25^{\circ} \mathrm{C}$.

It is believed that UAE with NADES as extraction solvents, due to their high viscosity, is less efficient than the conventional method of extraction (CE) [69]. Maceration via stirring is $\mathrm{CE}$ for the recovery of biologically active compounds from brown seaweeds [33,70]. NADES are viscous substances. Heating decreases viscosity [4] and boosts the convection and mass transfer from the seaweed matrix [71]. Further, we compared the compounds yields extracted with ethanol (using PE at $25^{\circ} \mathrm{C}$ ), NADES (UAE- $60 \mathrm{~min}, 25^{\circ} \mathrm{C}$ ), and NADES $\left(\mathrm{CE}\right.$ at $60^{\circ} \mathrm{C}$ ) from the F. vesiculosus material. The heating and dilution of NADES with $30 \%$ of water $(w / w)$ promotes a significant increase in the recovery of all compounds by NADES (Figure 4). The most promising results were obtained for NADES2. The yield of $\mathrm{AA}, \mathrm{TPhC}$, and FX was increased by 3.2, 6.5, and 5.9 folds, respectively, when compared to UAE extraction at $25^{\circ} \mathrm{C}$ for $20 \mathrm{~min}$ (Table 2). Whereas the yields of TPhC and FX extracted with NADES (CE, at $60^{\circ} \mathrm{C}$; Figure 4) was equal to those of with NADES (UAE-60 min, at $25^{\circ} \mathrm{C}$; Figure 3). However, the recovery of AA in NADES using CE (at $60^{\circ} \mathrm{C}$ ) was lower than that of UAE- $60 \mathrm{~min}\left(\right.$ at $\left.25^{\circ} \mathrm{C}\right)$. This could be due to the possible degradation of AA at intensive stirring and heating. We consider that the UAE for $60 \mathrm{~min}$ at $25^{\circ} \mathrm{C}$ is preferable for greater recovery of all lipophilic and hydrophilic compounds from F. vesiculosus.

\subsection{Antioxidant Activity}

DPPH assay is a well-accepted method for the analysis of the antioxidant activity of seaweed extracts $[36,39,42,43]$. The DPPH assay results are demonstrated in Figure 5. The data indicate that the method and conditions of extraction play a key role in the antioxidant activity of extracts. The lowest activity was observed for extracts received by the $\mathrm{CE}$ method. DPPH scavenging activity of extracts obtained by the UAE significantly rises with the extraction time. The extension of the extraction time, up to $60 \mathrm{~min}$, resulted in the increase of activity by 2.4 folds for the NADES1 extract and 2.2 folds for the NADES2 extract when compared to 20 min UAE. The NADES1 extract, prepared by UAE for $60 \mathrm{~min}$, showed $78.5 \pm 1.4 \%$ DPPH scavenging (Figure 5 ). This activity was significantly higher than the activity of the PE extract. The experimental data evidenced that NADES with $30 \mathrm{wt} \%$ water shows excellent ability for the extraction of compounds from seaweeds with 
potent antioxidant activity. This corroborates with Ummat et al. (2020), who reported that, compared with $\mathrm{CE}$, ultrasound facilitated the release of polyphenols from the seaweed, which leads to increased DPPH scavenging activity of UAE extracts [43].

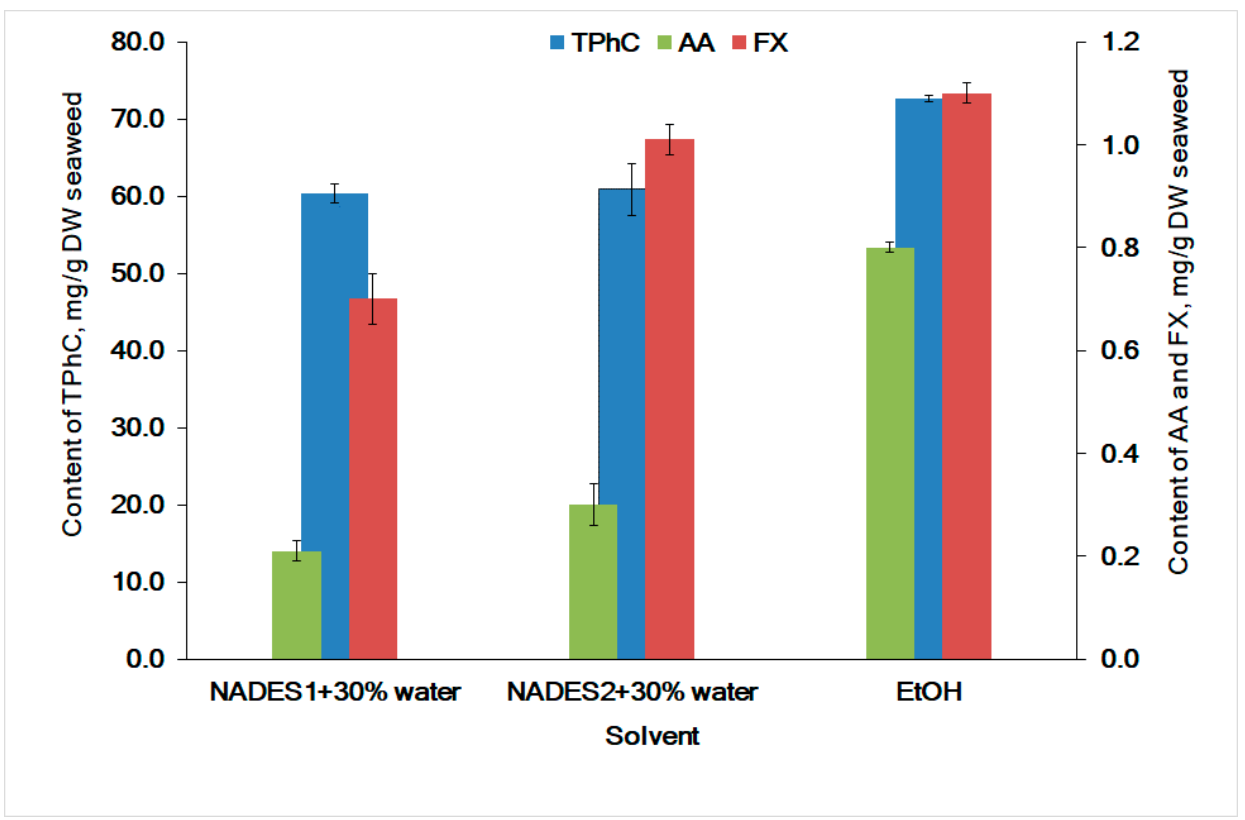

Figure 4. Comparison of extraction efficacy of ascorbic acid (AA), total phlorotannins (TPhC), and fucoxanthin (FX) from F. vesiculosus with NADES (CE at $60^{\circ} \mathrm{C}$ ) and with EtOH by exhaustive extraction $\left(\mathrm{PE}, 25^{\circ} \mathrm{C}\right)$.

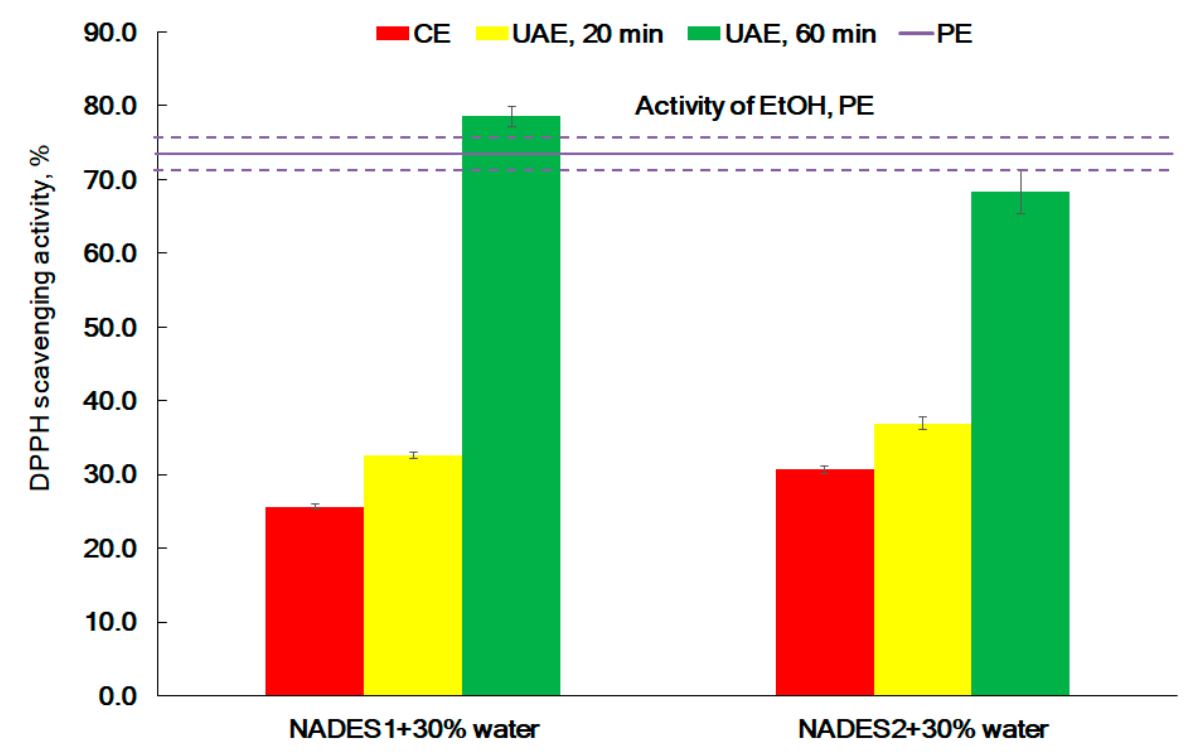

Figure 5. The effect of the extraction method $\left(\mathrm{CE}\left(60^{\circ} \mathrm{C}\right), \mathrm{UAE}-20 \mathrm{~min}\left(25^{\circ} \mathrm{C}\right), \mathrm{UAE}-60 \mathrm{~min}\left(25^{\circ} \mathrm{C}\right)\right.$, and $\left.\mathrm{PE}\left(25^{\circ} \mathrm{C}\right)\right)$ on the antiradical activity of the NADES extracts from F. vesiculosus.

Pearson's correlation analysis evidenced that all hydrophilic and lipophilic compounds observed in this study handle the antioxidant activity. A positive correlation was observed between DPPH scavenging activity and AA $(0.76, p<0.0000)$, as well as TPhC $(0.46, p<0.02)$ and FX contents $(0.55, p<0.006)$. The correlation was also found between $\mathrm{AA}$ and TPhC $(0.87, p<0.0000)$, while there was no significant correlation with $\mathrm{TPhC}$ and FX, indicating that some individual compounds or fractions could contribute more than others to the antioxidant properties of the F. vesiculosus extracts. A similar positive 
correlation between antioxidant activity and FX and TPhC from seaweeds was observed by other authors [41]. The hydroxyl group in AA and TPhC are responsible for the potent antioxidant activities $[43,53]$. While the activity of FX is associated with conjugated double bonds and the presence of the peroxide group and allenic bond in the terminal rings of FX [39].

\subsection{Determination of the Mixture Effect}

The natural crude extracts represent a mixture of different compounds. The discovery of the impact of individual compounds/fractions on the antioxidant activities of natural extracts is challenging [36,72]. The mixture effect (ME) is one of the common approaches for expressing the synergistic or antagonistic effects occurring between pairs of antioxidants in a mixture [72,73]. To investigate $\mathrm{ME}$, solutions of AA and phloroglucinol and their mixture were prepared and their ability to scavenge DPPH radicals was studied. Based on the data obtained for the individual solutions and extracts (NADES1, NADES2, and EtOH), the DPPH scavenging activity was calculated after $30 \mathrm{~min}$. Mathematically, ME > 1 evidence regards the synergistic effect between antioxidants, whereas $\mathrm{ME}<1$ indicates antagonism. In the case of $\mathrm{ME}=1$, neither a synergistic nor an antagonistic effect exists.

The antioxidant activity for a model mixture of AA and phloroglucinol showed that they have a strong synergistic effect on the reaction with the DPPH radical (ME = 2.99). The PE extract had a pronounced synergistic effect (ME 2.03). In the experiments with $\mathrm{UAE}$, the extension of the sonication time from $20 \mathrm{~min}$ up to $60 \mathrm{~min}$ was favorable for ME. The ME for the extracts with NADES1 and NADES 2 increased from 0.99 to 1.96 and from 1.00 to 2.27 , respectively. In contrast, $\mathrm{CE}$ at $60{ }^{\circ} \mathrm{C}$ does not lead to the synergistic effect (ME 0.94 and 1.04 for NADES1 and NADES2, respectively). The increased AA and FX content in the NADES2 extract compared to the NADES1 extract (Figure 4) can explain the slightly higher ME for NADES2. The UAE extracts were more beneficial due to the higher concentration of AA and FX in these extracts (Figure 3) compared to CE (Figure 4) and potent antioxidant activities (Figure 5). Although the content of FX in seaweed extracts is lower than the content of TPhC, FX contributes to the antioxidant activity as well [74]. The synergy of antioxidants from seaweeds has been claimed in several papers [36,74,75]. To the best of our knowledge, the synergistic effect for antioxidants extracted by NADES from seaweeds is calculated in this article for the first time.

\subsection{Storage Stability}

NADES are not only green solvents for natural compounds, but also enhance their stability [62,69]. Phlorotannins were the most abundant metabolite in the studied extracts of F. vesiculosus. Therefore, we have monitored the effects of solvents and storage time on the stability of phlorotannins in NADES and EtOH extracts. Both the content of TPhC in the extracts and the appropriate antiradical activity were determined during storage at $25{ }^{\circ} \mathrm{C}$ in a dark place for 360 days. The results showed that after 30 days of storage the content of TPhC in EtOH began to decline considerably faster compared with the TPhC in both NADES (Figure 6a). NADES1 enables greater stability of the phlorotannins, while about $70 \%$ of the phlorotannins degraded in $\mathrm{EtOH}$ after 360 days of the experiment. The stability of TPhC in the extracts (Figure 6a) was correlated with the antioxidant activity (Figure 6b). 


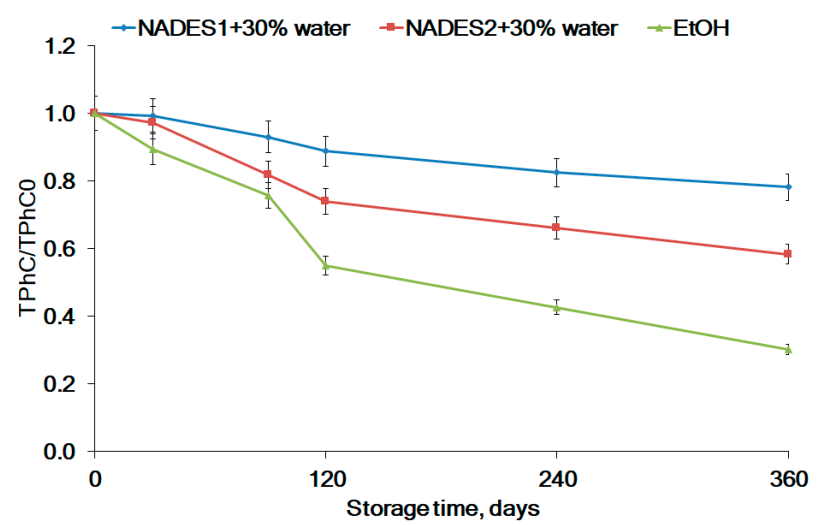

(a)

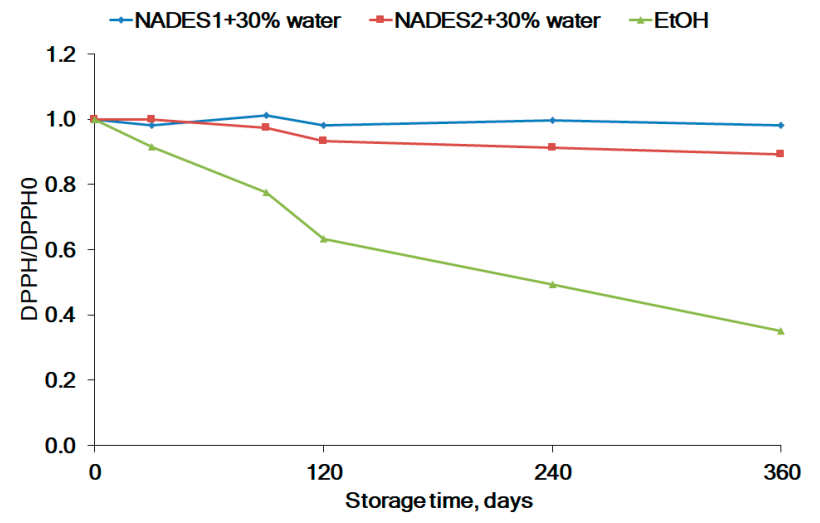

(b)

Figure 6. (a) The dynamic of the total phlorotannins content (TPhC) and (b) DPPH scavenging activity during the storage of F. vesiculosus extracts at $25^{\circ} \mathrm{C}$ in a dark place for 360 days.

Our results are in agreement with literature data in which NADES provides better stability for carthamin [76], anthocyanins [69], and curcumin [15]. The stabilization ability of NADES may have a direct relationship to their viscosity [76]. The total water content in NADES1 is less than in NADES2. The water content in NADES1 is $30 \%(w / w)$, while NADES2 contained three moles of water after preparation (Table 1 ) and $30 \%$ water $(w / w)$ was added after tuning of solvents (Section 2.1). The dilution with water decreases the viscosity of NADES2 compared to NADES1. The higher viscosity of NADES negatively affects the movement of molecules, allowing a stable interaction between the molecules of the NADES components and the solutes. This leads to a reduction in the contact time for metabolites on the NADES surface with air and consequently resulted in less oxidative degradation [69]. Additionally, oxygen has a lower solubility in NADES than in ethanol or water. The solubility and physical stability of some pharmaceuticals in NADES have also been reported recently [77]. Results of our experiments suggest that NADES enable not only the better stability of active metabolites from F. vesiculosus, but also preserve the antioxidant activity of extracts.

\section{Materials and Methods}

\subsection{Materials and Reagents}

Fresh brown seaweeds Fucus vesiculosus L. were collected from the coastal region

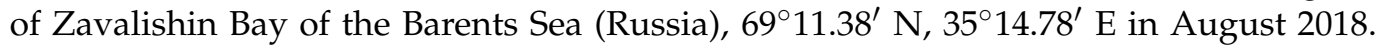
The seaweeds were washed twice in filtered seawater and cleaned from epiphytes by carefully rubbing its surface. The samples were frozen and stored at $-25^{\circ} \mathrm{C}$ for later extraction. The dry weight was determined from $3 \times 5 \mathrm{~g}$ of fresh seaweed material, which was dried at $40{ }^{\circ} \mathrm{C}$ in the drying oven (UM 200, Memmert GmbH + Co. KG, Germany). The seaweeds were identified by Dr. E. Obluchinskaya and the voucher specimens (No. 8.2018, V.D.Z.) were deposited in the Collection of the Zoobentos Laboratory, Murmansk Marine Biology Institute. L-Lactic acid and D(+)-glucose were from Panreac Química SLU (Barcelona, Spain). The Folin-Ciocalteu reagent, ascorbic acid, phloroglucinol, and 2,2-diphenyl-1-picrylhydrazyl (DPPH) were from Sigma-Aldrich (St. Louis, MO, USA) and the fucoxanthin was from Supelco (Bellefonte, PA, USA). Choline chloride was purchased from Acros Organics (Fair Lawn, NJ, USA). The water was purified via a Milli-Q system (Millipore, Bedford, MA, USA). Other analytical grade chemicals and solvents for extraction and assay were purchased from local chemical suppliers.

\subsection{NADES Preparation}

A heating method [4] was used for the preparation of the NADES. Lactic acid and hydrogen bond donors glucose or choline chloride, at the respective molar ratio, were 
used [23]. The pre-weighed components (Table 1) were placed in a bottle and heated in a water bath at $50{ }^{\circ} \mathrm{C}$ for $60 \mathrm{~min}$ with agitation at $700 \mathrm{rpm}$ until a clear liquid was formed. The water-containing NADES were obtained by a dilution of NADES with water based on $\%$ weight.

\subsection{Extraction Conditions}

Frozen samples of $F$. vesiculosus were cut into small pieces of about $1-3 \mathrm{~mm}^{2}$, thawed for $2 \mathrm{~h}$ at room temperature, and then mixed at a ratio of 1:10 $(w / v)$ with one of the solvent. The ultrasound-assisted extraction (UAE) was performed using a Branson MT3510 ultrasonic bath (Branson Ultrasonics Corporation, Danbury, CT, USA) at $42 \mathrm{kHz}$, $130 \mathrm{~W}$ for 20 and $60 \mathrm{~min}$. After the sonication, the samples were centrifuged at $3000 \times g$ for $15 \mathrm{~min}$ at $20^{\circ} \mathrm{C}$ and a liquid layer was used for future analysis. Conventional extraction (CE) was performed by maceration with magnetic stirring $(1 \mathrm{~h}, 700 \mathrm{rpm})$ and heating at $60{ }^{\circ} \mathrm{C}$. For percolation extraction (PE), the sample of F. vesiculosus was wetted with $96 \%$ $\mathrm{EtOH}$ for $24 \mathrm{~h}$ and then percolated [52] with the same solvent at a ratio of $1: 10$ at $25^{\circ} \mathrm{C}$. All the extraction procedures were performed in triplicate.

\subsection{Analysis of Hydrophilic and Lipophilic Compounds}

The amount of total phlorotannins content (TPhC) in the extracts was determined according to [78]. Briefly, $100 \mu \mathrm{L}$ of sample or phloroglucinol was mixed with $2 \mathrm{~mL}$ of $2 \%$ $\mathrm{Na}_{2} \mathrm{CO}_{3}$ and after 2 min was added $100 \mu \mathrm{L}$ of Folin-Ciocalteau reagent. The solutions were mixed and incubated for $30 \mathrm{~min}$ at room temperature in dark conditions. The absorbance of the reaction was measured at $720 \mathrm{~nm}$ using a spectrophotometer Shimadzu UV 1800 (Shimadzu, Kyoto, Japan). The TPhC was expressed as mg phloroglucinol equivalents per gram (mg PGE/g) DW of seaweed.

Fucoxanthin (FX) was analyzed using a reverse-phase high performed liquid chromatography (RP-HPLC) at room temperature [79] with a Shimadzu (Kyoto, Japan) HPLC system comprising of two LC20AD pumps, a DGU-20 A3 degasser, and a SPD.M20 A diode-array detector. Separation was achieved on a $4.6 \mathrm{~mm}$ i.d. $\times 250 \mathrm{~mm}, 5 \mu \mathrm{m}$ particle, C18 column (Phenomenex, Torrance, CA, USA) with a SecurityGuard pre-column ( $2 \mathrm{~mm}$ ) containing the same adsorbent (Phenomenex). Isocratic elution was performed with acetonitrile-methanol 95:5 $(v / v)$ as mobile phase at a flow rate of $1 \mathrm{~mL} / \mathrm{min}$. The sample injection volume was $20 \mu \mathrm{L}$. A Shimadzu LC Solution data-analysis system was used. Chromatograms were registered at $450 \mathrm{~nm}$ and the quantification of FX was executed via the calibration curve, with fucoxanthin as a reference. The content of FX was expressed as $\mathrm{mg}$ of $\mathrm{FX} / \mathrm{g}$ DW of seaweed.

Ascorbic acid (AA) was determined by HPLC, as described previously [80], in slight modification. Briefly, $1.0 \mathrm{~g}$ of extract was dissolved in $5 \mathrm{~mL}$ of water. Isocratic elution was performed with $0.03 \%$ aqueous trifluoroacetic acid-methanol 95:5 $(v / v)$ as mobile phase; the flow rate was $1.0 \mathrm{~mL} / \mathrm{min}$. The detection wavelength was $240 \mathrm{~nm}$. Sample volume was $20 \mu \mathrm{L}$ and each sample was analyzed in triplicate. The calibration curve with AA as a standard was used to calculate the AA in extracts. The content of AA was expressed as mg of $\mathrm{AA} / \mathrm{g} \mathrm{DW}$.

\subsection{Antioxidant Activity}

The DPPH free radical reacts directly with the antioxidants. The DPPH scavenging activity was analyzed, as previously reported [81]. Briefly, $1 \mathrm{~mL}$ of sample or standard was mixed well with $1.5 \mathrm{~mL} \mathrm{H}_{2} \mathrm{O}$ and $0.5 \mathrm{~mL}$ of $100 \mu \mathrm{M}$ DPPH methanolic solution in a test tube. AA was used as positive control. The same concentration of methanol and DPPH was used as the control without AA or extract. The reactive solutions were left in darkness at room temperature for $30 \mathrm{~min}$. Then, the absorbance at $517 \mathrm{~nm}$ was taken using 
a UV-Vis spectrophotometer Shimadzu UV 1800 (Shimadzu, Kyoto, Japan). The percentage of antioxidant activity in the different samples was calculated as:

$$
\text { DPPH scavenging activity }(\%)=\frac{\mathrm{A}_{\text {control }}-\mathrm{A}_{\text {sample }}}{\mathrm{A}_{\text {control }}} \times 100
$$

where $\mathrm{A}_{\text {control }}$ is the absorbance of the control and $\mathrm{A}_{\text {sample }}$ is the absorbance of the sample.

\subsection{Determination of Mixture Effect}

The mixture effect (ME) of the two antioxidants could be defined as the experimental value, divided by the calculated value, in which the sum of the effects of the two antioxidants is obtained individually [72]. The ME, in the case of the DPPH assay [73], was computed by comparing the experimental DPPH scavenging activity of the extract ("experimental DPPH scav.act.") with the expected DPPH scavenging activity, calculated by the sum of efficiencies of each compound individually ("calculated DPPH scav.act.")

$$
\mathrm{ME}=\frac{\text { experimental DPPH scav.act. }}{\text { calculated DPPH scav.act. }}
$$

\subsection{Storage Stability Test}

The stability of the NADES1, NADES2, and EtOH extracts was tested. The extracts were stored at $25^{\circ} \mathrm{C}$ in the dark and samples of each group were analyzed after 30, 90, 120, 240 , and 360 days.

\subsection{Statistical Analysis}

All statistical analyses were performed using STATGRAPHICS Centurion XV software (StatPoint Technologies Inc., USA). The data are expressed as mean \pm standard deviation $( \pm \mathrm{SD})$ and the error bars in the figures indicate the standard deviation. Differences between the means were analyzed via the ANOVA test, followed by the post-hoc Tukey's test. A significant difference was considered at the level of $p<0.05$. Pearson's correlation coefficients were used to establish the relationship between the content of the representative compounds and the antioxidant capacity.

\section{Conclusions}

In this paper, we report for the first time lactic acid: choline chloride and lactic acid: glucose: water-based NADES are suitable for the simultaneous extraction of hydrophilic (ascorbic acid and phlorotannins) and lipophilic (fucoxanthin) compounds from F. vesiculosus. The efficacy of UAE for $60 \mathrm{~min}$ was, for different compounds, 1.1-2.7 folds higher than the conventional extraction (maceration with stirring at $60^{\circ} \mathrm{C}$ ). In biological tests, both NADES extracts showed the favorable ability to scavenge DPPH radicals which were equal to the antioxidant activity of EtOH extract. Ascorbic acid, TPhC, and FX significantly contributed to the DPPH scavenging activity of extracts. We calculated the synergistic effect for antioxidants extracted by NADES from F. vesiculosus based on the mixture effect for the first time. Notably, NADES, besides their reduced environmental impact, enable high stability for active metabolites from $F$. vesiculosus and preserve the antioxidant activity of extracts. Thus, the results of our experiments highlight the potential of NADES for the recovery of hydrophilic and lipophilic compounds from F. vesiculosus.

Supplementary Materials: The following are available online, Figure S1: Typical chromatogram of ascorbic acid (reference), Figure S2: Typical chromatogram of Fucus vesiculosus extract obtained with NADES1 (conventional extraction), Figure S3: Typical chromatogram of Fucus vesiculosus extract obtained with NADES1 (ultrasound assisted extraction), Figure S4: Typical chromatogram of fucoxanthin (reference), Figure S5: Typical chromatogram of Fucus vesiculosus extract obtained with EtOH (percolation), Figure S6: Typical chromatogram of Fucus vesiculosus extract obtained with 
NADES1 (ultrasound assisted extraction), Figure S7. Typical chromatogram of Fucus vesiculosus extract obtained with NADES2 (ultrasound assisted extraction).

Author Contributions: Conceptualization, O.N.P. and A.N.S.; methodology, E.D.O. and O.N.P.; investigation, E.D.O., L.V.Z., A.V.D., and O.N.P.; data curation, O.N.P., E.V.F., and A.N.S.; writingoriginal draft preparation, E.D.O., L.V.Z., A.V.D., O.N.P., E.V.F., and A.N.S.; writing-review and editing, E.D.O., O.N.P., E.V.F., and A.N.S. All authors have read and agreed to the published version of the manuscript.

Funding: This study was conducted within the framework of the Government Assignment to the Murmansk Marine Biological Institute Russian Academy of Sciences (Russia) (basic funding).

Data Availability Statement: The data presented in this study are available in supplementary material.

Conflicts of Interest: The authors declare no conflict of interest.

Sample Availability: Samples of the extracts are available from the authors.

\section{References}

1. Fourmenti, S.; Gomes, M.C.; Lichtfouse, E. Deep Eutectic Solvents for Medicine, Gas Solubilization and Extraction of Natural Substances; Springer: Cham, Switzerland, 2020. [CrossRef]

2. Fu, X.; Wang, D.; Belwal, T.; Xu, Y.; Li, L.; Luo, Z. Sonication-synergistic natural deep eutectic solvent as a green and efficient approach for extraction of phenolic compounds from peels of Carya cathayensis Sarg. Food Chem. 2021, 355, 129577. [CrossRef]

3. Choi, Y.H.; Van Spronsen, J.; Dai, Y.; Verberne, M.; Hollmann, F.; Arends, I.W.; Witkamp, G.J.; Verpoorte, R. Are natural deep eutectic solvents the missing link in understanding cellular metabolism and physiology? Plant Physiol. 2011, 156, 1701-1705. [CrossRef]

4. Dai, Y.; Van Spronsen, J.; Witkamp, G.J.; Verpoorte, R.; Choi, Y.H. Natural deep eutectic solvents as new potential media for green technology. Anal. Chim. Acta 2013, 766, 61-68. [CrossRef]

5. Bubalo, M.C.; Vidović, S.; Redovniković, I.R.; Jokić, S. New perspective in extraction of plant biologically active compounds by green solvents. Food Bioprod. Process. 2018, 109, 52-73. [CrossRef]

6. Takla, S.S.; Shawky, E.; Hammoda, H.M.; Darwish, F.A. Green techniques in comparison to conventional ones in the extraction of Amaryllidaceae alkaloids: Best solvents selection and parameters optimization. J. Chromatogr. A. 2018, 1567, 99-110. [CrossRef]

7. Bosiljkov, T.; Dujmić, F.; Bubalo, M.C.; Hribar, J.; Vidrih, R.; Brnčić, M.; Zlatic, E.; Redovnicović, I.; Jokić, S. Natural deep eutectic solvents and ultrasound-assisted extraction: Green approaches for extraction of wine lees anthocyanins. Food Bioprod. Process. 2017, 102, 195-203. [CrossRef]

8. Velásquez, P.; Bustos, D.; Montenegro, G.; Giordano, A. Ultrasound-assisted extraction of anthocyanins using natural deep eutectic solvents and their incorporation in edible films. Molecules 2021, 26, 984. [CrossRef]

9. Fu, X.; Wang, D.; Belwal, T.; Xie, J.; Xu, Y.; Li, L.; Zou, L.; Zhang, L.; Luo, Z. Natural deep eutectic solvent enhanced pulseultrasonication assisted extraction as a multi-stability protective and efficient green strategy to extract anthocyanin from blueberry pomace. LWT 2021, 144, 111220. [CrossRef]

10. Shikov, A.N.; Kosman, V.M.; Flissyuk, E.V.; Smekhova, I.E.; Elameen, A.; Pozharitskaya, O.N. Natural deep eutectic solvents for the extraction of phenyletanes and phenylpropanoids of Rhodiola rosea L. Molecules 2020, 25, 1826. [CrossRef]

11. Nicolae, C.V.; Trică, B.; Doncea, S.M.; Marinas, I.C.; Oancea, F.; Constantinescu-Aruxandei, D. Evaluation and optimization of polysaccharides and ferulic acid solubility in NADES using surface response methodology. Proceedings 2019, 29, 96. [CrossRef]

12. Oomen, W.W.; Begines, P.; Mustafa, N.R.; Wilson, E.G.; Verpoorte, R.; Choi, Y.H. Natural deep eutectic solvent extraction of flavonoids of Scutellaria baicalensis as a replacement for conventional organic solvents. Molecules 2020, 25, 617. [CrossRef] [PubMed]

13. Wu, Y.C.; Wu, P.; Li, Y.B.; Liu, T.C.; Zhang, L.; Zhou, Y.H. Natural deep eutectic solvents as new green solvents to extract anthraquinones from Rheum palmatum L. RSC Adv. 2018, 8, 15069-15077. [CrossRef]

14. Rodrigues, L.A.; Pereira, C.V.; Leonardo, I.C.; Fernández, N.; Gaspar, F.B.; Silva, J.M.; Reis, R.L.; Duarte, A.R.C.; Paiva, A.; Matias, A.A. Terpene-Based natural deep eutectic systems as efficient solvents to recover astaxanthin from brown crab shell residues. ACS Sustain. Chem. Eng. 2020, 8, 2246-2259. [CrossRef]

15. Jeliński, T.; Przybyłek, M.; Cysewski, P. Natural deep eutectic solvents as agents for improving solubility, stability and delivery of curcumin. Pharm. Res. 2019, 36, 1-10. [CrossRef] [PubMed]

16. Lanjekar, K.J.; Rathod, V.K. Green extraction of Glycyrrhizic acid from Glycyrrhiza glabra using choline chloride based natural deep eutectic solvents (NADESs). Process Biochem. 2021, 102, 22-32. [CrossRef]

17. Ivanovic, M.; Alanon, M.E.; Arraez-Roman, D.; Segura-Carretero, A. Enhanced and green extraction of bioactive compounds from Lippia citriodora by tailor-made natural deep eutectic solvents. Food Res. Int. 2018, 111, 67-76. [CrossRef]

18. Yang, G.-Y.; Song, J.-N.; Chang, Y.-Q.; Wang, L.; Zheng, Y.-G.; Zhang, D.; Guo, L. Natural deep eutectic solvents for the extraction of bioactive steroidal saponins from Dioscoreae Nipponicae rhizoma. Molecules 2021, 26, 2079. [CrossRef] 
19. Wils, L.; Leman-Loubière, C.; Bellin, N.; Clément-Larosière, B.; Pinault, M.; Chevalier, S.; Enguehard-Gueiffier, C.; Leslie, C.; Boudesocque-Delaye, L. Natural deep eutectic solvent formulations for spirulina: Preparation, intensification, and skin impact. Algal Res. 2021, 56, 102317. [CrossRef]

20. Tang, W.; Row, K.H. Design and evaluation of polarity controlled and recyclable deep eutectic solvent based biphasic system for the polarity driven extraction and separation of compounds. J. Clean. Prod. 2020, 268, 122306. [CrossRef]

21. Cicci, A.; Sed, G.; Bravi, M. Potential of choline chloride-based natural deep eutectic solvents (NaDES) in the extraction of microalgal metabolites. Chem. Eng. Trans. 2017, 57, 61-66. [CrossRef]

22. Mahmood, W.M.A.W.; Lorwirachsutee, A.; Theodoropoulos, C.; Conzalez-Miguel, M. Polyol-based deep eutectic solvents for extraction of natural polyphenolic antioxidants from Chlorella vulgaris. ACS Sustain. Chem. Eng. 2019, 7, 5018-5026. [CrossRef]

23. Obluchinskaya, E.D.; Daurtseva, A.V.; Pozharitskaya, O.N.; Flisyuk, E.V.; Shikov, A.N. Natural Deep Eutectic Solvents as alternatives for extracting phlorotannins from brown algae. Pharm. Chem. J. 2019, 53, 243-247. [CrossRef]

24. Shang, X.C.; Chu, D.; Zhang, J.X.; Zheng, Y.F.; Li, Y. Microwave-assisted extraction, partial purification and biological activity in vitro of polysaccharides from bladder-wrack (Fucus vesiculosus) by using deep eutectic solvents. Sep. Purif. Technol. 2021, 259, 118169. [CrossRef]

25. Catarino, M.D.; Silva, A.M.S.; Cardoso, S.M. Phycochemical constituents and biological activities of Fucus spp. Mar. Drugs 2018, 16, 249. [CrossRef] [PubMed]

26. Heavisides, E.; Rouger, C.; Reichel, A.F.; Ulrich, C.; Wenzel-Storjohann, A.; Sebens, S.; Tasdemir, D. Seasonal variations in the metabolome and bioactivity profile of Fucus vesiculosus extracted by an optimised, pressurised liquid extraction protocol. Mar. Drugs 2018, 16, 503. [CrossRef]

27. Vahtmae, E.; Kotta, J.; Orav-Kotta, H.; Kotta, I.; Parnoja, M.; Kutser, T. Predicting macroalgal pigments (chlorophyll a, chlorophyll $\mathrm{b}$, chlorophyll a plus b, carotenoids) in various environmental conditions using high-resolution hyperspectral spectroradiometers. Int. J. Remote Sens. 2018, 39, 5716-5738. [CrossRef]

28. Oliveira, C.; Granja, S.; Neves, N.M.; Reis, R.L.; Baltazar, F.; Silva, T.H.; Martins, A. Fucoidan from Fucus vesiculosus inhibits new blood vessel formation and breast tumor growth in vivo. Carbohydr. Polym. 2019, 223, 115034. [CrossRef]

29. Pozharitskaya, O.N.; Obluchinskaya, E.D.; Shikov, A.N. Mechanisms of bioactivities of fucoidan from the brown seaweed Fucus vesiculosus L. of the Barents Sea. Mar. Drugs 2020, 18, 275. [CrossRef]

30. Zayed, A.; Ulber, R. Fucoidans: Downstream processes and recent applications. Mar. Drugs 2020, 18, 170. [CrossRef]

31. Holdt, S.L.; Kraan, S. Bioactive compounds in seaweed: Functional food applications and legislation. J. Appl. Phycol. 2011, 23, 543-597. [CrossRef]

32. Bogolitsyn, K.; Dobrodeeva, L.; Druzhinina, A.; Ovchinnikov, D.; Parshina, A.; Shulgina, E. Biological activity of a polyphenolic complex of Arctic brown algae. J. Appl. Phycol. 2019, 31, 3341-3348. [CrossRef]

33. Catarino, M.D.; Silva, A.M.S.; Mateus, N.; Cardoso, S.M. Optimization of phlorotannins extraction from Fucus vesiculosus and evaluation of their potential to prevent metabolic disorders. Mar. Drugs 2019, 17, 162. [CrossRef]

34. Catarino, M.D.; Silva, A.; Cruz, M.T.; Mateus, N.; Silva, A.M.S.; Cardoso, S.M. Phlorotannins from Fucus vesiculosus: Modulation of inflammatory response by blocking NF-кB signaling pathway. Int. J. Mol. Sci. 2020, 21, 6897. [CrossRef]

35. Heffernan, N.; Brunton, N.P.; FitzGerald, R.J.; Smyth, T.J. Profiling of the molecular weight and structural isomer abundance of macroalgae-derived phlorotannins. Mar. Drugs 2015, 13, 509-528. [CrossRef]

36. Hermund, D.B.; Plaza, M.; Turner, C.; Jonsdottir, R.; Kristinsson, H.G.; Jacobsen, C.; Nielsen, K.F. Structure dependent antioxidant capacity of phlorotannins from Icelandic Fucus vesiculosus by UHPLC-DAD-ECD-QTOFMS. Food Chem. 2018, 240, 904-909. [CrossRef]

37. Chapman, V.J.; Chapman, D.J. Minor Uses of Algae and Their Products, 3rd ed.; Chapman and Hall Ltd.: New York, NY, USA, 1980.

38. Mikami, K.; Hosokawa, M. Biosynthetic pathway and health benefits of fucoxanthin, an algae-specific xanthophyll in brown seaweeds. Int. J. Mol. Sci. 2013, 14, 13763-13781. [CrossRef]

39. Koduvayur Habeebullah, S.F.; Surendraraj, A.; Jacobsen, C. Isolation of fucoxanthin from brown algae and its antioxidant activity: In vitro and 5\% fish oil-in-water emulsion. J. Am. Oil Chem. Soc. 2018, 95, 835-843. [CrossRef]

40. Qiu, S.; Shen, Y.; Wu, Z.; Zhang, X.; Ge, S. Effects of algae subtype and extraction condition on extracted fucoxanthin antioxidant property: A 20-year meta-analysis. Algal Res. 2021, 53, 102161. [CrossRef]

41. Foo, S.C.; Yusoff, F.M.; Ismail, M.; Basri, M.; Yau, S.K.; Khong, N.M.H.; Chan, K.W.; Ebrahimi, M. Antioxidant capacities of fucoxanthin-producing algae as influenced by their carotenoid and phenolic contents. J. Biotechnol. 2017, 241, 175-183. [CrossRef]

42. Gheda, S.; Naby, M.A.; Mohamed, T.; Pereira, L.; Khamis, A. Antidiabetic and antioxidant activity of phlorotannins extracted from the brown seaweed Cystoseira compressa in streptozotocin-induced diabetic rats. Environ. Sci. Pollut. Res. Int. 2021, $28,1-16$. [CrossRef] [PubMed]

43. Ummat, V.; Tiwari, B.K.; Jaiswal, A.K.; Condon, K.; Garcia-Vaquero, M.; O’Doherty, J.; O’Donnell, C.; Rajauria, G. Optimisation of ultrasound frequency, extraction time and solvent for the recovery of polyphenols, phlorotannins and associated antioxidant activity from brown seaweeds. Mar. Drugs 2020, 18, 250. [CrossRef]

44. Cardoso, S.M.; Pereira, O.R.; Seca, A.M.L.; Pinto, D.C.G.A.; Silva, A.M.S. Seaweeds as preventive agents for cardiovascular diseases: From nutrients to functional foods. Mar. Drugs 2015, 13, 6838-6865. [CrossRef]

45. Cornish, M.L.; Critchley, A.T.; Mouritsen, O.G. Consumption of seaweeds and the human brain. J. Appl. Phycol. 2017, 29, 2377-2398. [CrossRef] 
46. Pradhan, B.; Nayak, R.; Patra, S.; Jit, B.P.; Ragusa, A.; Jena, M. Bioactive metabolites from marine algae as potent pharmacophores against oxidative stress-associated human diseases: A comprehensive review. Molecules 2021, 26, 37. [CrossRef] [PubMed]

47. Radošević, K.; Ćurko, N.; Gaurina Srček, V.; Cvjetko Bubalo, M.; Tomašević, M.; Kovačević Ganić, K.; Radojčić Redovniković, I. Natural Deep Eutectic Solvents as beneficial extractants for enhancement of plant extracts bioactivity. LWT Food Sci. Technol. 2016, 73, 45-51. [CrossRef]

48. Vanda, H.; Dai, Y.; Wilson, E.G.; Verpoorte, R.; Choi, Y.H. Green solvents from ionic liquids and deep eutectic solvents to natural deep eutectic solvents. Comptes Rendus Chim. 2018, 21, 628-638. [CrossRef]

49. Sumampouw, G.A.; Jacobsen, C.; Getachew, A.T. Optimization of phenolic antioxidants extraction from Fucus vesiculosus by pressurized liquid extraction. J. Appl. Phycol. 2021, 33, 1195-1207. [CrossRef]

50. Saravana, P.S.; Getachew, A.T.; Cho, Y.J.; Choi, J.H.; Park, Y.B.; Woo, H.C.; Chun, B.S. Influence of co-solvents on fucoxanthin and phlorotannin recovery from brown seaweed using supercritical CO2. J. Supercrit. Fluid. 2017, 120, 295-303. [CrossRef]

51. Amarante, S.J.; Catarino, M.D.; Marçal, C.; Silva, A.M.S.; Ferreira, R.; Cardoso, S.M. Microwave-Assisted extraction of phlorotannins from Fucus vesiculosus. Mar. Drugs 2020, 18, 559. [CrossRef]

52. Singh, J. Maceration, Percolation and Infusion Techniques for the Extraction of Medicinal and Aromatic Plants. In Extraction Technologies for Medicinal and Aromatic Plants; Handa, S.S., Khanuja, S.P.S., Longo, G., Rakesh, D.D., Eds.; ICS-UNIDO: Trieste, Italy, 2008; pp. 67-82.

53. Um, M.; Han, T.H.; Lee, J.W. Ultrasound-assisted extraction and antioxidant activity of phenolic and flavonoid compounds and ascorbic acid from rugosa rose (Rosa rugosa Thunb.) fruit. Food Sci. Biotech. 2018, 27, 375-382. [CrossRef] [PubMed]

54. Kim, S.M.; Jung, Y.J.; Kwon, O.N.; Cha, K.H.; Um, B.H.; Chung, D.; Pan, C.H. A potential commercial source of fucoxanthin extracted from the microalga Phaeodactylum tricornutum. Appl. Biochem. Biotechnol. 2012, 166, 1843-1855. [CrossRef] [PubMed]

55. Xia, S.; Wang, K.; Wan, L.; Li, A.; Hu, Q.; Zhang, C. Production, characterization, and antioxidant activity of fucoxanthin from the marine diatom Odontella aurita. Mar. Drugs 2013, 11, 2667-2681. [CrossRef]

56. Ling, J.K.U.; San Chan, Y.; Nandong, J.; Chin, S.F.; Ho, B.K. Formulation of choline chloride/ascorbic acid natural deep eutectic solvent: Characterization, solubilization capacity and antioxidant property. LWT 2020, 133, 110096. [CrossRef]

57. Maneffa, A.J.; Harrison, A.B.; Radford, S.J.; Whitehouse, A.S.; Clark, J.H.; Matharu, A.S. Deep eutectic solvents based on natural ascorbic acid analogues and choline chloride. ChemistryOpen 2020, 9, 550. [CrossRef]

58. Miyashita, K.; Beppu, F.; Hosokawa, M.; Liu, X.; Wang, S. Bioactive significance of fucoxanthin and its effective extraction. Biocatal. Agric. Biotechnol. 2020, 26, 101639. [CrossRef]

59. Roy, V.C.; Ho, T.C.; Lee, H.J.; Park, J.S.; Nam, S.Y.; Lee, H.; Getachew, A.T.; Chun, B.S. Extraction of astaxanthin using ultrasoundassisted natural deep eutectic solvents from shrimp wastes and its application in bioactive films. J. Clean. Prod. 2021, 284, 125417. [CrossRef]

60. Liu, Y.; Friesen, B.; McAlpine, J.B.; Lankin, D.C.; Chen, S.-N.; Pauli, G.F. Natural deep eutectic solvents: Properties, applications, and perspectives. J. Nat. Prod. 2018, 81, 679-690. [CrossRef] [PubMed]

61. Benvenutti, L.; Zielinski, A.A.F.; Ferreira, S.R.S. Which is the best food emerging solvent: IL, DES or NADES? Trends Food Sci. Technol. 2019, 90, 133-146. [CrossRef]

62. Percevault, L.; Limanton, E.; Gauffre, F.; Lagrost, C.; Paquin, L. Extraction of Plant and Algal Polyphenols Using Eutectic Solvents. In Deep Eutectic Solvents for Medicine, Gas Solubilization and Extraction of Natural Substances; Fourmentin, S., Costa Gomes, M., Lichtfouse, E., Eds.; Springer International Publishing: Cham, Switzerland, 2021; Volume 56, pp. 241-306. [CrossRef]

63. Santos, S.A.O.; Félix, R.; Pais, A.C.S.; Rocha, S.M.; Silvestre, A.J.D. The Quest for phenolic compounds from macroalgae: A Review of extraction and identification methodologies. Biomolecules 2019, 9, 847. [CrossRef]

64. Dai, Y.; Witkamp, G.-J.; Verpoorte, R.; Choi, Y.H. Natural Deep Eutectic Solvents as a new extraction media for phenolic metabolites in Carthamus tinctorius L. Anal. Chem. 2013, 85, 6272-6278. [CrossRef]

65. Zhou, P.; Wang, X.; Liu, P.; Huang, J.; Wang, C.; Pan, M.; Kuang, Z. Enhanced phenolic compounds extraction from Morus alba L. leaves by deep eutectic solvents combined with ultrasonic-assisted extraction. Ind. Crop. Prod. 2018, 120, 147-154. [CrossRef]

66. Fu, X.; Belwal, T.; Cravotto, G.; Luo, Z. Sono-physical and sono-chemical effects of ultrasound: Primary applications in extraction and freezing operations and influence on food components. Ultrason. Sonochem. 2020, 60, 104726. [CrossRef]

67. Chemat, F.; Rombaut, N.; Sicaire, A.G.; Meullemiestre, A.; Fabiano-Tixier, A.S.; Abert-Vian, M. Ultrasound assisted extraction of food and natural products. Mechanisms, techniques, combinations, protocols and applications. A review. Ultrason. Sonochem. 2017, 34, 540-560. [CrossRef]

68. Aguilar, K.; Garvín, A.; Ibarz, A.; Augusto, P.E. Ascorbic acid stability in fruit juices during thermosonication. Ultrason. Sonochem. 2017, 37, 375-381. [CrossRef] [PubMed]

69. Dai, Y.; Rozema, E.; Verpoorte, R.; Choi, Y.H. Application of natural deep eutectic solvents to the extraction of anthocyanins from Catharanthus roseus with high extractability and stability replacing conventional organic solvents. J. Chromatogr. A 2016, 1434, 50-56. [CrossRef] [PubMed]

70. Li, Y.; Fu, X.; Duan, D.; Liu, X.; Xu, J.; Gao, X. Extraction and identification of phlorotannins from the brown alga, Sargassum fusiforme (Harvey) Setchell. Mar. Drugs 2017, 15, 49. [CrossRef] [PubMed]

71. Grosso, C.; Valentão, P.; Ferreres, F.; Andrade, P.B. Alternative and efficient extraction methods for marine-derived compounds. Mar. Drugs 2015, 13, 3182-3230. [CrossRef] 
72. Peyrat-Maillard, M.N.; Cuvelier, M.E.; Berset, C. Antioxidant activity of phenolic compounds in 2,2'-azobis (2-amidinopropane) dihydrochloride (AAPH)-induced oxidation: Synergistic and antagonistic effects. J. Am. Oil Chem. Soc. 2003, 80, 1007-1012. [CrossRef]

73. Pozharitskaya, O.N.; Shikov, A.N.; Kosman, V.M.; Selezneva, A.I.; Urakova, I.N.; Makarova, M.N.; Makarov, V.G. Immunomodulatory and antioxidants properties of fixed combination of fish oil with plant extracts. Synergy 2015, 2, 19-24. [CrossRef]

74. Airanthi, M.W.A.; Hosokawa, M.; Miyashita, K. Comparative antioxidant activity of edible Japanese brown seaweeds. J. Food Sci. 2011, 76, C104-C111. [CrossRef] [PubMed]

75. Martins, C.D.L.; Ramlov, F.; Carneiro, N.P.N.; Gestinari, L.M.; dos Santos, B.F.; Bento, L.M.; Lhullier, C.; Gouvea, L.; Bastos, E.; Horta, P.A. Antioxidant properties and total phenolic contents of some tropical seaweeds of the Brazilian coast. J. Appl. Phycol. 2013, 25, 1179-1187. [CrossRef]

76. Dai, Y.; Verpoorte, R.; Choi, Y.H. Natural deep eutectic solvents providing enhanced stability of natural colorants from safflower (Carthamus tinctorius). Food Chem. 2014, 159, 116-121. [CrossRef] [PubMed]

77. Mustafa, N.R.; Spelbos, V.S.; Witkamp, G.-J.; Verpoorte, R.; Choi, Y.H. Solubility and stability of some pharmaceuticals in natural deep eutectic solvents-based formulations. Molecules 2021, 26, 2645. [CrossRef] [PubMed]

78. Rajauria, G.; Foley, B.; Abu-Ghannam, N. Identification and characterization of phenolic antioxidant compounds from brown Irish seaweed Himanthalia elongata using LC-DAD-ESI-MS/MS. Innov. Food Sci. Emerg. Technol. 2016, 37, 261-268. [CrossRef]

79. Daurtseva, A.V.; Obluchinskaya, E.D. The stability of pigments in the thalli and extracts of the Barents Sea fucus algae. Vestnik of MSTU 2019, 22, 314-321. [CrossRef]

80. Urakova, I.N.; Pozharitskaya, O.N.; Shikov, A.N.; Kosman, V.M.; Makarov, V.G. Development and validation of an LC method for simultaneous determination of ascorbic acid and three phenolic acids in sustained release tablets at single wavelength. Chromatographia 2008, 67, 709-713. [CrossRef]

81. Wang, T.; Jónsdóttir, R.; Ólafsdóttir, G. Total phenolic compounds, radical scavenging and metal chelation of extracts from icelandic seaweeds. Food Chem. 2009, 116, 240-248. [CrossRef] 